\title{
CUA-AUA International Fellows Program: Boston 2017
}

\author{
Nathan Colin Wong, MD \\ McMaster University, Hamilton, ON, Canada
}

Cite as: Can Urol Assoc J 2017;1 1 (8):230. hrtrp://dx.doi.org/10.5489/cuaj.4818

7 he Canadian Urological Association (CUA) aims to foster excellence in urological practice through advocacy, education, research, and practice support tools. Throughout my residency, I have been thankful for the role the CUA has played as an integral foundation to building my career, and the CUA-AUA International Fellows Program is another important example of this. The program provided the opportunity to experience the American Urological Association's (AUA's) $112^{\text {th }}$ Annual Meeting in Boston, MA. The meeting featured access to innovative research, up-to-date clinical guidelines, diverse courses and forums, and state-of-the-art technologies in urology, all of which I am excited to share with my colleagues and incorporate into my future care.

Prior to the AUA, the CUA-AUA International Fellows Program organized an online WebEx orientation, providing fellows with the tools necessary to effectively navigate the meeting. With an interest in urological oncology, I attended the Society of Urologic Oncology meeting and oncologyfocused sessions, which exposed me to advanced research and networking opportunities with colleagues, while stimulating ideas for future research endeavors.

At a moderated poster session, a group from Memorial Sloan Kettering presented a phase 3, double-blinded, randomized, placebo-controlled trial comparing the effects of intravenous mannitol to normal saline prior to renal ischemia during nephron-sparing surgery on renal function outcomes. ${ }^{1}$ Although mannitol has long been considered a renoprotective agent, there have been no randomized, controlled trials performed in humans to date. The authors demonstrated that mannitol did not lead to any clinically relevant improvements in renal function outcomes with respect to changes in estimated glomerular filtration rate (eGFR) and renal scans. This Level 1 evidence suggests that mannitol may not be necessary in this setting and that other renoprotective agents should be investigated.

Perhaps the most exciting data presented at the AUA were the results of the prospective, multicentre, randomized open vs. robotic radical cystectomy (RAZOR) trial. ${ }^{2}$ Presented at the late-breaking abstract session, this non-inferiority trial of patients with cT1-4, N0-1, M0 bladder cancer or refractory cTis included 151 patients randomized to robotic cystectomy and 156 randomized to open cystectomy with all diversions performed extracorporeally. The authors showed that two-year progression free survival, overall survival, overall surgical margins, lymph node yield, and complication rates were statistically similar between the two groups. Compared to the open approach, however, robotic cystectomy was associated with significantly lower blood loss, lower transfusion rates, and shorter lengths of stay, but longer operative times. There was also a statistically higher bladder soft tissue margin rates in the robotic cohort that was unfortunately not discussed in further detail.

At the conclusion of the AUA meeting, program fellows gathered to discuss conference highlights with the CUA Education Advisory Council. We had the opportunity to present insights, critically appraise abstracts, and assess how findings would impact our future careers as Canadian urologists. This was the highlight of the fellows program, as I was able to share my AUA experience and subsequently re-experience the meeting from the perspective of my colleagues. I would like to thank my peers, industry sponsors, and the CUA for this exceptional opportunity.

Competing interests: The author reports no competing personal or financial interests.

\section{References}

1. Spaliviero M, Power NE, Murray KS, et al. MP49-01 Phase 3 randomized trial of intravenous mannitol vs. placebo prior to renal ischemia during nephron-sparing surgery: Impact on renal functional outcomes. J Urol 2017;194:e646. https://doi.org/10.1016/i.juro.2017.02.1503

2. Parekh D. PNFLBA-18 A prospective, multicenter, randomized trial of open vs. robotic radical cystectomy (RAZOR). J Urol 2017;197:e918. https://doi.org/10.1016/i.juro.2017.03.044

Correspondence: Dr. Nathan Colin Wong, McMaster University, Hamilton, ON, Canada; nathan.wong@medportal.ca 